\title{
Analysis of gene expression EGFR and KRAS, microRNA-21 and microRNA-203 in patients with colon and rectal cancer and correlation with clinical outcome and prognostic factors ${ }^{1}$
}

Thais Inácio de Carvalho', Paulo Cezar Novais", Fermino Sanches Lizarte Neto"', Renata Danielle

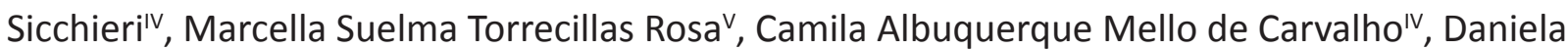
Pretti da Cunha Tirapelliv', Fernanda Maris Peria ${ }^{\mathrm{VII}}$, José Joaquim Ribeiro da Rocha ${ }^{\mathrm{VIII}}$, Omar Féres ${ }^{\mathrm{IX}}$

'PhD, Postgraduate Program in Clinical Surgery, Department of Surgery and Anatomy, School of Medicine of Ribeirao Preto, Universidade de São Paulo (USP), Brazil. Acquisition and interpretation of data, manuscript writing.

"PhD, Department of Health Sciences, Universidade de Marília (UNIMAR), Pos-doctoral Fellow, Postgraduate Program in Clinical Surgery, Department of Surgery and Anatomy, School of Medicine of Ribeirao Preto, USP, Brazil. Technical procedures, manuscript writing.

I'Pos-doctoral Fellow, Postgraduate Program in Clinical Surgery, Department of Surgery and Anatomy, School of Medicine of Ribeirao Preto, USP, Brazil. Technical procedures, manuscript writing.

${ }^{\mathrm{V}}$ Fellow PhD degree, Postgraduate Program in Clinical Surgery, Department of Surgery and Anatomy, School of Medicine of Ribeirao Preto, USP, Brazil. Manuscript writing.

${ }^{\vee}$ Fellow Master degree, Postgraduate Program in Clinical Surgery, Department of Surgery and Anatomy, School of Medicine of Ribeirao Preto, USP, Brazil. Manuscript writing.

V'PhD, Department of Surgery and Anatomy, Postgraduate Program in Clinical Surgery, School of Medicine of Ribeirao Preto, USP, Brazil. Scientific and intellectual content of the study.

VIIPhD, Department of Medical Clinical, Oncology Program, School of Medicine of Ribeirão Preto, USP, Brazil. Scientific and intellectual content of the study.

VIIIAssociate Professor, Coloproctology Division, Department of Surgery and Anatomy, School of Medicine of Ribeirao Preto, USP, Brazil. Scientific and intellectual content of the study.

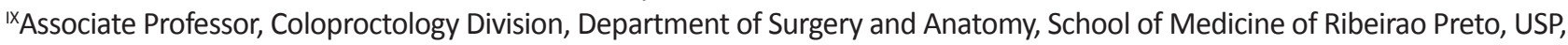
Brazil. Concept, design, intellectual and scientific content of the study; supervision of all phases of the study, critical revision.

\section{Abstract}

Purpose: To evaluate the expression of EGFR, KRAS genes, microRNAs-21 and 203 in colon and rectal cancer samples, correlated with their age at diagnosis, histological subtype, value of pretreatment CEA, TNM staging and clinical outcome.

Methods: Expression of genes and microRNAs by real time PCR in tumor and non-tumor samples obtained from surgical treatment of 50 patients.

Results: An increased expression of microRNAs-21 and 203 in tumor samples in relation to nontumor samples was found. There was no statistically significant difference between the expression of these genes and microRNAs when compared to age at diagnosis and histological subtype. The EGFR gene showed higher expression in relation to the value of CEA diagnosis. The expression of microRNA-203 was progressively lower in relation to the TNM staging and was higher in the patient group in clinical remission.

Conclusions: The therapy of colon and rectum tumors based on microRNAs remains under investigation reserving huge potential for future applications and clinical interventions in conjunction with existing therapies. We expect, based on the exposed data, to stimulate the development of new therapeutic possibilities, making the treatment of these tumors more effective.

Key words: Colonic Neoplasms. Rectal Neoplasms. Genes, erbB-1. MicroRNAs. 


\section{- Introduction}

Colon and rectal cancer is found in the first places in incidence of neoplasms, varying the position according to gender and socioeconomic development. Despite all the advances in treating this cancer, it still occupies the first place also in mortality ${ }^{1}$.

In spite of being about $90 \%$ pure adenocarcinoma $^{2}$, this neoplasia presents diversity in its clinical course. Several prognostic factors have been proposed, such as age, value of pretreatment carcinoembryonic antigen (CEA), histological subtype, tumor grade and others, but the greatest impact is the TNM staging, that serves as a basis for therapeutic decisions. But even with the updates and frequent revisions we observe different clinical outcomes in patients of the same TNM staging subgroup. The development of molecular biology has contributed to a better understanding of cancer development, predicting its evolution. therapeutic response and even developing molecular target. Even for the treatment of metastatic colorrectal cancer, there are already available for clinical use, an antibody against epidermal growth factor receptor (EGFR) ${ }^{3}$ and other against the vascular endothelial growth factor (VEGF).

However, despite the EGFR being expressed in $25-75 \%$ of colon and rectal cancer ${ }^{3}$, this antibody therapeutic response occurs in only some patients ${ }^{5}$. The EGFR has shown to be predictive factor of response for the use of this antibody ${ }^{6}$. Since the mutation $\mathrm{KRAS}^{7}$ and $\mathrm{BRAF}^{5}$, which are part of the intracellular cascade below EGFR, are associated with response to use of the antibodies against the EGFR.

microRNAs are small molecules, noncoding RNA 22nt nucleotides (nt) that regulate gene expression. It is estimated that about $30 \%$ of human genes are regulated by microRNAs ${ }^{8}$. The role of microRNA depends on its messenger RNA in a target tissue. MicroRNA can act as tumor suppressor or oncogene ${ }^{9}$. As microRNAs have a small sequence and act without complete pairing, one can regulate many microRNA targets with totally different functions ${ }^{10}$. The altered expression of microRNAs has been correlated with various tumor types $^{11}$, and it is being associated with tumor classification, diagnosis, staging, prognostic and predictive factors ${ }^{12}$.

In the present study we evaluated the expression of EGFR gene, KRAS, microRNA-21 (miR-21) and microRNA-203 (miR-203) in colon cancer samples, straight and correlated with patients' age at diagnosis, histological subtype, value of pretreatment CEA, TNM staging and clinical outcome.

\section{Methods}

After been approved by the Research Ethics Committee, a prospective study was performed with 50 consecutive Colorectal cancer patients undergoing curative surgery at Clinics Hospital - Universidade de São Paulo (Ribeirão Preto-SP), from April 2008 to February 2009.

All patients signed a free and informed consent form for enrollment in the study. Exclusion criteria included genetic CRC related to genetic syndromes, inflammatory disease and tumors that were not adenocarcinomas and the refusal to provide written informed consent.

Variables collected from medical records included gender, age, tumor site, histologic subtype, pre-operative CEA, TNM staging and clinical outcome. As control samples we collected 20 samples of adjacent non-tumor tissue from CRC patients during the surgery.

\section{RNA purification}

The samples were stored at $-80^{\circ} \mathrm{C}$ until RNA extraction. For this procedure, 250 $\mu \mathrm{L}$ of PBS and $750 \mu \mathrm{L}$ of TRIZOL (Invitrogen, Carlsbad, CA, USA) were added to the tissue 
samples, which were then lysed in a Polytron homogenizer for about 3 min. Next, total RNA was extracted by the TRIZOL method, according to the manufacturer's instructions. All RNA samples were quantified by spectrophotometry (NanoDrop 2000 Spectrophotometer) and a $260 / 280$ ratio ranging from 1.8 to 2.0 was used to exclude low-purity samples.

\section{Gene qPCR analysis}

The system TaqMan Assay-on-demand (Applied Biosystems, Foster City, CA, USA) was used to analyze genes: EGFR (Assay ID Hs01076078_m1) and KRAS (Assay ID Hs00978051_g1). Complementary DNA (cDNA) was synthesized by reverse transcription using a commercial High Capacity cDNA Reverse Transcription Kit (Applied Biosystems, Foster City, CA, USA - \#4368814) according to the manufacturer's manual (500 ng of RNA per sample), using a thermociclator. For the real time $\mathrm{PCR}$, the conditions were pre-heating at $50^{\circ} \mathrm{C}$ for $2 \mathrm{~min}$, denaturation at $95^{\circ} \mathrm{C}$ for $10 \mathrm{~min}$, and 40 cycles of amplification and quantification (15 s at $95^{\circ} \mathrm{C}$ and $1 \mathrm{~min}$ at $60^{\circ} \mathrm{C}$ ). GAPDH (Assay ID Hs02758991_g1) was selected as endogenous control (housekeeping) for gene reactions.

\section{miRNA qPCR analysis}

The cDNA was synthesized using 2.5 ng of RNA. The specific looped RT primers for miR-21 and miR-203 and reagents were included in the High Capacity c-DNA archive Kit (Applied Biosystems), and these components were incubated with RNase Inhibitor (Applied Biosystems) for $30 \mathrm{~min}$ at $16^{\circ} \mathrm{C}, 30 \mathrm{~min}$ at $42^{\circ} \mathrm{C}$, $5 \mathrm{~min}$ at $85^{\circ} \mathrm{C}$, and then held at $4^{\circ} \mathrm{C}$. Real-time PCR analysis of cDNA was performed at $95^{\circ} \mathrm{C}$ for $10 \mathrm{~min}$, followed by 40 cycles at $95^{\circ} \mathrm{C}$ for 15 $\mathrm{s}$ and $60^{\circ} \mathrm{C}$ for $1 \mathrm{~min}$ in a 7500 Real Time PCR System using TaqMan Reaction Master Mix (Applied Biosystems), in accordance with the manufacturer's instructions. For such, we used the following primers: has-miR-21 and hasmiR-203 (Applied Biosystems). The U6 were used as endogenous controls (housekeeping) for miRNA reactions.

\section{Statistical analysis}

For descriptive analysis of patients median and quartiles were used, since it is a Gaussian distribution and unpaired. The molecular analysis of the results obtained by real-time PCR was performed using GraphPad Prism 6.0 software that generated graphs and statistical analysis. For comparative analysis of subgroups not unpaired and Gaussian distribution we opted for the Mann-Whitney and Kruskal-Wallis test according to the number of subgroups evaluated, and considered statistically significant $p<0.05$.

\section{Results}

\section{Sample analysis of patients}

The clinical and pathological characteristics of patients are shown in Table 1, 50 samples were studied, being 25 male and 25 female samples. The age at diagnosis ranged from 27 to 89 years, many patients were older than 60 years old. The primary tumors were observed in the colon of 28 patients and in the rectum of 22 patients. The histological subtypes pure adenocarcinoma and mucinous adenocarcinoma were found in 42 and 8 patients, respectively. $92 \%$ of the histological tumors were classified as moderately differentiated.

The staging of patients following the American Classification Joint Committee on Cancer, AJCC, Seventh Edition, showed one patient classified as stage I, 21 patients as stage II, 17 patients as stage III and 11 patients stage IV.

In three patients CEA was not measured before the start of chemotherapy and in others 
dosage to CEA ranged from 0.26 to $182 \mathrm{ng} / \mathrm{dL}$. Most of the patients had CEA less than $5 \mathrm{ng} / \mathrm{dL}$ regardless of the stage.

All patients underwent primary tumor resection, and for $22 \%$ of these patients no other treatment was administered. Most patients received chemotherapy, which was considered adjuvant in $58 \%$ and palliative in $18 \%$. Only six patients underwent radiotherapy (RT) at some time of treatment. None of the patients received molecular target treatment, probably due to the high cost of this therapy, which is not covered by the Unified Health System in Brazil.

Based on the data recovered from the clinical charts from the patients included in our sample, after a median follow up of 33 months, 28 patients remained in clinical remission; 13 patientes had already recurred, 4 had local recurrence and nine metastatic recurrence. Only four patients lost their follow up.

\section{Molecular analysis of the sample}

Expression of EGFR and KRAS gene showed no significant difference between colorectal cancer group and control group $(p=0.2858$ and $p=0.5857$, respectively). Yet the expression of miR-21 and miR-203 were higher in colorectal cancer group when compared to the control group $(p=0.0353$ and $p=0.0032$, respectively) (Figure 1 ).

Comparative analysis of the age and the molecular results

The expression of the KRAS gene and miRNAs-21, 203 showed a trend to be higher in patients who were diagnosed with cancer at an age below 60, but that was not statistically significant $(p=0.175, p=0.2431$ and $p=0.076$, respectively), in other hand the EGFR expression had a trend to be lower in patients under 60 years of age at diagnosis, however not statistically significant either $(p=0.2308)$.
Table 1 - General characteristics of patients according to clinical and pathological stages.

\begin{tabular}{|c|c|}
\hline $\begin{array}{l}\text { Clinical and pathological } \\
\text { characteristics }\end{array}$ & $\begin{array}{l}\text { Number of } \\
\text { patients }\end{array}$ \\
\hline \multicolumn{2}{|l|}{ Sex } \\
\hline Males & 25 \\
\hline Females & 25 \\
\hline \multicolumn{2}{|l|}{ AGE (years) } \\
\hline$<45$ & 5 \\
\hline 45 to 60 & 15 \\
\hline$>60$ to 75 & 19 \\
\hline$>75$ & 11 \\
\hline \multicolumn{2}{|l|}{ Topography of primary tumor } \\
\hline Colon & 28 \\
\hline Rectum & 22 \\
\hline \multicolumn{2}{|l|}{ pT STAGING } \\
\hline $\mathrm{T} 1$ & 1 \\
\hline $\mathrm{T} 2$ & 5 \\
\hline T3 & 33 \\
\hline T4 & 11 \\
\hline \multicolumn{2}{|l|}{ pN STAGING } \\
\hline NO & 27 \\
\hline N1 & 10 \\
\hline N2 & 13 \\
\hline \multicolumn{2}{|l|}{ TNM } \\
\hline 1 & 1 \\
\hline II & 21 \\
\hline III & 17 \\
\hline IV & 11 \\
\hline \multicolumn{2}{|l|}{ Angiolymphatic invasion } \\
\hline Present & 18 \\
\hline Absent & 18 \\
\hline No information & 14 \\
\hline \multicolumn{2}{|l|}{ CEA } \\
\hline$<5 \mathrm{ng} / \mathrm{dl}$ & 27 \\
\hline 5 a $15 \mathrm{ng} / \mathrm{dl}$ & 10 \\
\hline$>15$ a $50 \mathrm{ng} / \mathrm{dl}$ & 10 \\
\hline$>50 \mathrm{ng} / \mathrm{dl}$ & 3 \\
\hline
\end{tabular}

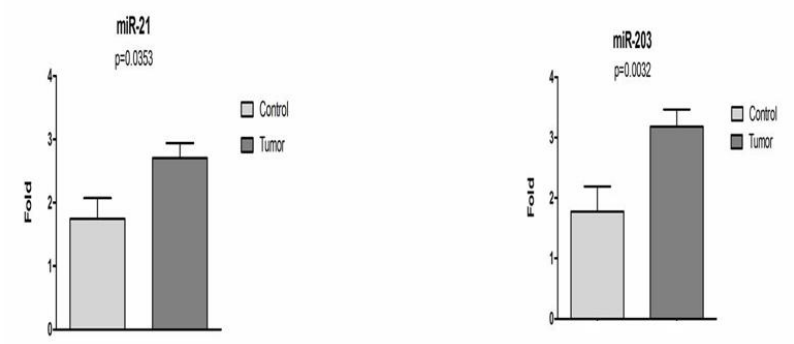

Figure 1 - Analysis of miR-21 and miR-203 expression in tumor and control samples. 
Comparative analysis of histological subtype and molecular results

The expression of the KRAS gene and miR-203 tended to be more expressed in the histological subtype of colon rectal cancer samples, but that was not statistically significant ( $p=0.7415$ and $p=0.119$, respectively). Moreover, expression of the EGFR gene and miR-21 was not statistically significant among the histological subtypes $(p=0.6531$ and $p=0.7233$, respectively).

Comparative analysis of the value of CEA and molecular results

The higher the value of CEA before the start of cancer treatment $(p=0.0151)$ the more the expression of EGFR gene increased (Figure 2).

The miR-203 expression also showed results similar to the expression of the EGFR gene, but that was not statistically significant $(p=0.1278)$.

Yet, the expression of the KRAS gene and miR-21 showed no statistically significant difference in the variation of the CEA prior to the start of cancer treatment $(p=0.8608$ and $p=0.9398$, respectively).
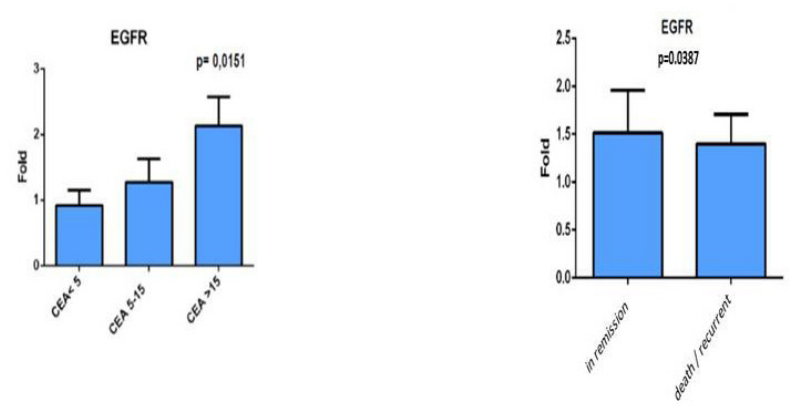

Figure 2 - Analysis of the expression of the EGFR gene compared to the amount of CEA before treatment and in relation to clinical outcome.

\section{Comparative analysis of the TNM staging and} molecular results

The higher the TNM staging of the patients, the lower the expression of miR$203(p=0.0258)$ (Figure 3). The analysis of the others molecular expression, comparing the different tumor staging, showed no statistically significant difference.

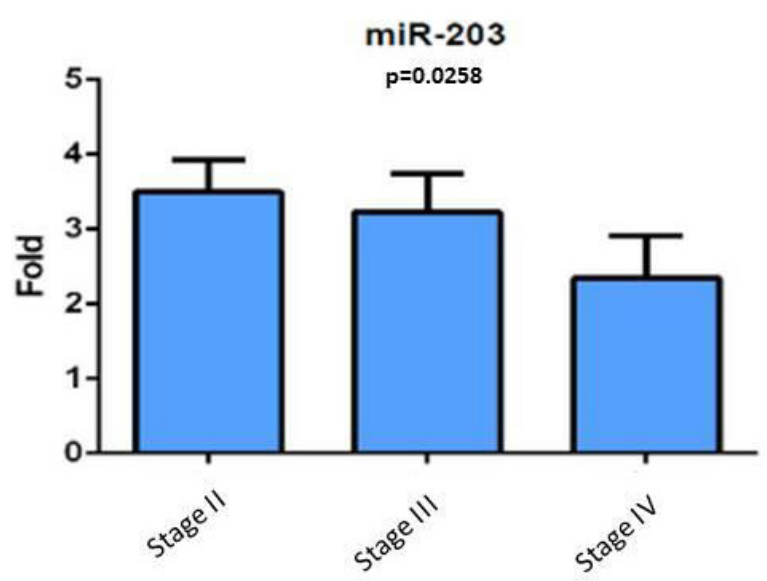

Figure 3 - miR-203 expression analysis in relation to the staging.

\section{Comparative analysis of clinical and molecular} results

For the analysis of the clinical outcome we considered a subgroup of patients who were in clinical remission and another subgroup of patients who had already evolved to relapse and or death.

The expressions of EGFR gene, KRAS and miR-21 showed no correlation with clinical outcome, although statistical significance was observed only in the result of the expression of the EGFR gene ( $p=0.0151)$ (Figure 2).

The expression of miR-203 was increased in the subgroup of patients who were in clinical remission ( $p=0.0104)$ (Figure 4). 


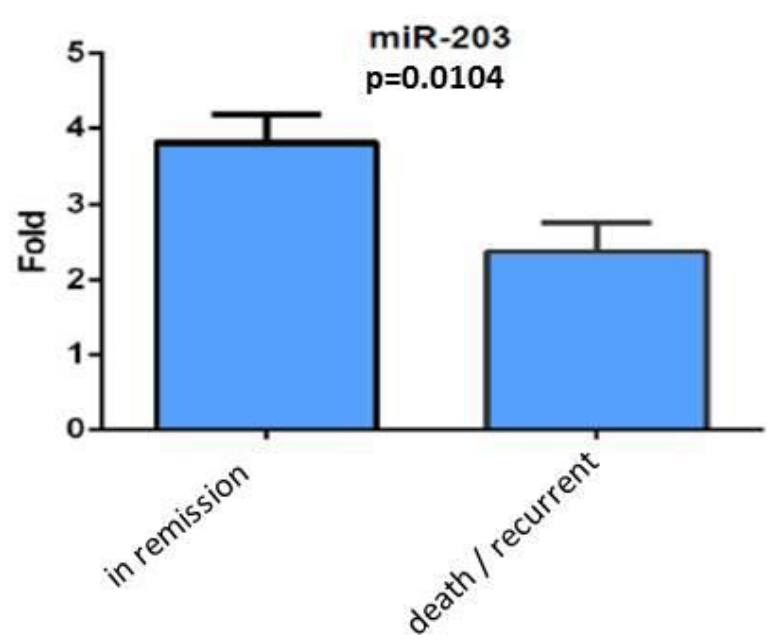

Figure 4 - Analysis of miR-203 expression with respect to clinical outcome.

\section{- Discussion}

Expression of miR-21 and miR-203 in the tumor tissue and non-tumor

Several microRNAs have already been described with altered expression correlated with various cancers. In a study using microarrays in colon and rectum cancer samples and adjacent non-tumor tissue showed five miRNAs (miR-20a, 21, 106a, 181b and 203) overexpressed in tumor samples and these were also analyzed by real time PCR and the results confirmed the increased expression of these microRNAs in tumor samples ${ }^{13}$. The miR-21 is significantly elevated in cancer of the colon and rectum, and is correlated with the regulation of multiple genes associated with the remodeling of the extracellular matrix and cell motility ${ }^{14}$. The overexpression of miRNas-21 is described in an early stage of the transformation of colonic mucosa in adenomas and also in later stages of tumor progression ${ }^{15}$. Compared to the described findings, similar results were demonstrated in our study in the analysis of the miRNAs-21, 203 expressions of the colon-rectal cancer samples.
Molecular correlation value and CEA before the initiation of treatment

CEA is a complex glycoprotein produced by $90 \%$ of colon and rectum cancers and contributestotumormalignancycharacteristics. However, in benign conditions it rarely exceeds the value of $10 \mathrm{ng} / \mathrm{dll}^{16}$. There are studies that correlate the increased preoperative CEA as a bad prognostic factor and still others analyze the value of CEA after the surgical resection of the tumor in non-metastatic disease, since it is expected that the amount of CEA should return to normal reference values about 4 to 6 weeks after surgery, if this doesn't occur, there is a correlation with worse patient outcomes ${ }^{17}$. Compared to the described findings, similar results were demonstrated in our study in the correlation of EGFR gene expression of colonrectal cancer samples with the value of CEA.

\section{Molecular correlation and staging}

Certainly the staging is the most important prognostic factor used in clinical practice. The TNM staging is considered the gold standard, from which patients can be separated in subgroups with similar clinical outcomes. In our study the expression of miR203 was progressively lower the higher the TNM staging of the patients. Moreover, it has been described that the low expression of miR203 is associated with more advanced tumors, as we considered in the analysis only the $\mathrm{T}$, there was no statistically significant difference between the low miR-203 expression with other pathological clinical variables such as tumor location, clinical stage and lymph node involvement ${ }^{18}$.

\section{Molecular correlation and clinical evolution}

Multiple factors influence the outcome of clinical evolution, including the general patient condition, presence of associated diseases, prognostic factors and clinical staging, histological subtype, surgery performed, access 
to medical treatment among other variables. Although colon cancer and non-metastatic rectal cancer have a naturally better clinical outcome and adjuvant treatment improving the disease free survival, $20-25 \%$ of stage II patients will evolve with recurrence and death $^{19}$.

Mckay et al. ${ }^{20}$ showed no correlation between the increased EGFR expression gene and disease progression in colon-rectal cancer samples. In our study we also found no correlation between EGFR expression and the progression of the disease, since this expression was similar in the group that remained in clinical remission and in the group that evolved to recurrence or death.

The expression of miR-203 was lower in samples from patients who have developed recurrent disease or death. The lower expression of this microRNA was associated with more advanced stages of tumor invasion in the intestinal wall of the TNM staging ${ }^{18}$.

The development of molecular biology has gradually been embedded in the clinic, especially in oncology. While very promising, this knowledge is still fresh. MicroRNAs were described at the beginning of the 1990s, and today we know that the function of this gene depends upon its target in a specific tissue, it can act either as a tumor suppressor or as an oncogene, since due to its short sequence and no need to complete pairing, a single microRNA can regulate many different target RNA messengers, with completely different functions ${ }^{10}$.

\section{Conclusions}

The expression of the EGFR gene was progressively higher in relation to the amount of pretreatment CEA. The expression of miRNAS-21 and 203 was higher in tumor compared to adjacent non-tumor samples. The expression of miR-203 was progressively lower in relation to the staging of the disease, moreover the expression of this miRNA was higher in patients who remained in clinical remission of cancer. The therapy of colon and rectum tumor based on microRNAs remains under investigation, reserving huge potential for future applications and clinical interventions in conjunction with existing therapies. We expect, based on the previously exposed data, that the modulation of molecular markers, including EGFR gene, KRAS, microRNA-21 (miR-21) and microRNA-203 (miR-203), will stimulate the development of new therapeutic possibilities, making the treatment of colon and rectum tumors more effective.

\section{References}

1. Jemal A, Bray F, Center MM, Ferlay J, Ward E, Forman D. Global cancer statistics. CA Cancer J Clin. 2011 Mar-Apr;61(2):69-90. PMID: 21296855.

2. Compton CC. Colorectal carcinoma: diagnostic, prognostic, and molecular features. Mod Pathol. 2003 Apr;16(4):37688. PMID: 12692203.

3. Harari PM. Epidermal growth factor receptor inhibition strategies in oncology. Endocr Relat Cancer. 2004 Dec;11(4):689-708. PMID: 15613446.

4. Hurwitz H, Fehrenbacher L, Novotny W, Cartwright T, Hainsworth J, Heim W, Berlin J, Baron A, Griffing S, Holmgren E, Ferrara N, Fyfe G, Rogers B, Ross R, Kabbinavar F. Bevacizumab plus irinotecan, fluorouracil, and leucovorin for metastatic colorectal cancer. N Engl J Med. 2004 Jun 3;350(23):2335-42. PMID: 15175435.

5. Pritchard CC, Grady WM. Colorectal cancer molecular biology moves into clinical practice. Gut. 2011 Jan;60(1):116-29. PMID: 20921207.

6. Lievre A, Bachet JB, Boige V, Cayre A, Le Corre $D$, Buc E, Ychou M, Bouché O, Landi B, Louvet C, André T, Bibeau F, Diebold MD, Rougier $\mathrm{P}$, Ducreux M, Tomasic G, Emile JF, PenaultLlorca F, Laurent-Puig P. KRAS mutations as an independent prognostic factor in patients with advanced colorectal cancer treated with cetuximab. Journal of clinical oncology: J Am Soc Clin Oncol. 2008 Jan 20;26(3):374-9. PMID: 18202412.

7. Bokemeyer C, Bondarenko I, Makhson A, 
Hartmann JT, Aparicio J, de Braud F, Donea S, Ludwig H, Schuch G, Stroh C, Loos AH, Zubel A, Koralewski P. Fluorouracil, leucovorin, and oxaliplatin with and without cetuximab in the first-line treatment of metastatic colorectal cancer. J Am Soc Clin Oncol. 2009 Feb 10;27(5):663-71. PMID: 19114683.

8. Garzon R, Calin GA, Croce CM. MicroRNAs in Cancer. Ann Rev Med. 2009;60:167-79. PMID: 19630570.

9. Croce CM. Oncogenes and cancer. N Engl J Med. 2008 Jan 31;358(5):502-11. PMID: 18234754.

10. Brennecke J, Stark A, Russell RB, Cohen SM. Principles of microRNA-target recognition. PLoS Biol. 2005 Mar;3(3):e85. PMID: 15723116.

11. Calin GA, Croce CM. MicroRNA-cancer connection: the beginning of a new tale. Cancer Res. 2006 Aug 1;66(15):7390-4. PMID: 16885332.

12. Calin GA, Croce CM. MicroRNA signatures in human cancers. Nature Rev Cancer. 2006 Nov;6(11):857-66. PMID: 17060945.

13. Schetter AJ, Leung SY, Sohn JJ, Zanetti KA, Bowman ED, Yanaihara N, Yuen ST, Chan TL, Kwong DL, Au GK, Liu CG, Calin GA, Croce $\mathrm{CM}$, Harris CC. MicroRNA expression profiles associated with prognosis and therapeutic outcome in colon adenocarcinoma. JAMA. 2008 Jan 30;299(4):425-36. PMID: 18230780.

14.Slaby O, Svoboda M, Michalek J, Vyzula R. MicroRNAs in colorectal cancer: translation of molecular biology into clinical application. Mol Cancer. 2009;8:102. PMID: 19912656.

15. Faber C, Kirchner T, Hlubek F. The impact of microRNAs on colorectal cancer. Virchows Arch. 2009 Apr;454(4):359-67. PMID: 19288129.

16. Duffy MJ. Carcinoembryonic antigen as a marker for colorectal cancer: is it clinically useful? Clin Chem. 2001 Apr;47(4):624-30. PMID: 11274010.

17. Filella X, Molina R, Pique JM, Grau JJ, GarciaValdecasas JC, Biete A, Novell F, Astudillo E, Bordas JM, Campo E. CEA as a prognostic factor in colorectal cancer. Anticancer Res. 1994 Mar-Apr;14(2B):705-8. PMID: 8010730.

18. Chiang Y, Song Y, Wang Z, Chen Y, Yue Z, Xu $H$, Xing $C$, Liu Z. Aberrant expression of miR203 and its clinical significance in gastric and colorectal cancers. J Gastrointest Surg. 2011 Jan;15(1):63-70. PMID: 21063914.

19. Schepeler T, Reinert JT, Ostenfeld MS, Christensen LL, Silahtaroglu AN, Dyrskjot L, Wiuf C, Sørensen FJ, Kruh øffer M, Laurberg $S$, Kauppinen S, Ørntoft TF, Andersen CL. Diagnostic and prognostic microRNAs in stage II colon cancer. Cancer Res. 2008 Aug 1;68(15):6416-24. PMID: 18676867.

20. McKay JA, Murray LJ, Curran S, Ross VG, Clark C, Murray GI, Cassidy J, McLeod HL. Evaluation of the epidermal growth factor receptor (EGFR) in colorectal tumours and lymph node metastases. Eur J Cancer. 2002 Nov;38(17):2258-64. PMID: 12441262.

\section{Correspondence:}

Thais Inácio de Carvalho

Faculdade de Medicina de Ribeirão Preto - USP

Avenida Bandeirantes, 3900

14049-900 Ribeirão Preto - SP Brasil

Tel.: (55 16)3315-3305

lab.biomol.cirurgia.fmrp.usp@gmail.com

Received: Nov 19, 2016

Review: Jan 17, 2017

Accepted: Feb 21, 2017
Conflict of interest: none

Financial source: none 